\title{
Targeted Treatment of Differentiated and Medullary Thyroid Cancer
}

\author{
Shannon R. Bales and Inder J. Chopra \\ Division of Endocrinology, Diabetes, and Hypertension, University of California, Los Angeles, CA 90095, USA \\ Correspondence should be addressed to Inder J. Chopra, ichopra@mednet.ucla.edu
}

Received 14 January 2011; Accepted 14 June 2011

Academic Editor: Nelson Wohllk

Copyright ( $) 2011$ S. R. Bales and I. J. Chopra. This is an open access article distributed under the Creative Commons Attribution License, which permits unrestricted use, distribution, and reproduction in any medium, provided the original work is properly cited.

The incidence of thyroid cancer is increasing, with a concomitant increase in the number of patients with advanced and metastatic disease. Discoveries regarding the pathogenesis of thyroid cancer have led to the recent development of new therapeutic agents that are beginning to appear on the market. Many of these new agents are targeted kinase inhibitors primarily affecting oncogenic kinases (BRAF V600E, RET/PTC) or signaling kinases (VEGFR, PDGFR). Some of these agents report significant partial response rates, while others attain stabilization of disease as their best response. Their impact on survival is unclear. While these agents target similar pathways, a wide variety of differences exist regarding efficacy and side effect profile. Current expert opinion advises that these agents be used only in a specific subset of patients.

\section{Introduction}

The incidence of thyroid cancer is increasing at an alarming rate. In fact, the incidence has more than doubled in the past fifty years, and it rose approximately $6 \%$ per year from 1997 to 2006 [1]. Peak incidence is in the early fifth decade for women and the late sixth decade for men. It is two to three times more common in women than in men, though mortality rates are higher in men. Mortality rates are also higher in patients with African ethnic heritage [1].

Total thyroidectomy followed by radioactive iodine $\left({ }^{131} \mathrm{I}\right)$ ablation and thyroid hormone suppression of serum TSH are the mainstay of treatment for differentiated thyroid cancer (DTC). While cure is generally attainable in welldifferentiated thyroid carcinomas (papillary and follicular subtypes), recurrence occurs in up to $40 \%$ of patients [2]. Unfortunately, in a small percentage of patients with thyroid cancer recurrence, the tumor becomes dedifferentiated. It does not concentrate iodine and thereby becomes unresponsive to $\left({ }^{131} \mathrm{I}\right)$ treatment, likely the result of mutational changes in the sodium-iodine symporter [3]. Such tumor often shows increased aggressiveness and has a tendency to metastasize $[4,5]$.
Patients with medullary thyroid cancer (MTC) are susceptible to early metastatic disease. Between 20 to $30 \%$ of patients with $\mathrm{T} 1$ tumors at the time of diagnosis already have metastasis to lymph nodes [6]. The mainstay of treatment for these patients is total thyroidectomy with aggressive lymph node dissection. For patients with a family history of MTC or multiple endocrine neoplasia $2 \mathrm{~A}$ or $2 \mathrm{~B}$, prophylactic thyroidectomy is recommended as soon as possible, even in patients who are less than one-year-old [6].

Popular treatment options for advanced stages of DTC and MTC consist of radiotherapy and chemotherapy, which confer only a modest benefit on tumor burden and overall survival. Current treatment regimens for advanced thyroid cancer include bleomycin, doxorubicin, platinumcontaining compounds, or a combination of these agents. For the most part, they result in minor responses, and their use is limited by their toxicities. Bleomycin is well known for its pulmonary toxicity, while doxorubicin can cause both cardiac arrhythmias and heart failure. Platinum-based therapies result in neuropathy, nausea, and renal toxicity [7].

However, recent research has shed light on the underlying molecular mechanisms of thyroid cancer and on the role of oncogenic kinases in metastatic thyroid cancer in particular 
[8]. Given the high incidence of thyroid cancer and its recently elucidated molecular mechanisms, thyroid cancer has become a focus of effort for use of new targeted therapies, especially the new class of agents that inhibit kinases involved in signaling, cellular growth, and angiogenesis [8]. Most of the therapeutic agents being developed actually target both the oncogenic and the signaling pathways.

\section{Overview of the Molecular Pathways of Thyroid Cancer}

Comprehensive studies of mutation pathways in DTC and MTC have been undertaken in the past two decades [921]. The knowledge gained from these analyses may render DTC and MTC amenable to designer therapeutics. The most important findings center on the discovery of oncogenic kinases, as well as the elucidation of various signaling pathway adaptations occurring in malignant cells. Of the oncogenic kinases, BRAF V600E mutation and RET/PTC mutations are being targeted as potential pathways for therapeutic intervention. Both of these mutations have the potential to activate the mitogen-activated protein kinase (MAPK) pathway downstream. Therapeutics targeting RET/PTC are being developed particularly for use in MTC. The vascular endothelial growth factor (VEGF) and platelet-derived growth factor (PDGF) pathways, as well as the phosphatidylinositol-3-kinase-(PI3K-) phosphatase with tensin homology (PTEN) pathway are important signaling cascades being investigated for possible development of therapeutic kinase inhibitors (Figure 1).

2.1. Oncogenic Kinases. BRAF mutations are the most commonly encountered mutation in PTC $[13,22,23]$. BRAF mutations are present in $29-83 \%$ of cases of papillary thyroid cancer (PTC) $[8,24]$. Anaplastic thyroid carcinoma (ATC) also has a high frequency of BRAF mutations, with up to $50 \%$ of ATC harboring a mutation in this entity [25]. The BRAF gene is located on chromosome 7q24. Oncogenic BRAF mutations in PTC commonly (approximately 80\%) are comprised of a thymidine to adenine substitution in exon 15 (T1799A) resulting in an amino acid sequence change of valine to glutamate (V600E) $[22,26]$. This change destabilizes the inactive conformation of BRAF, rendering it constitutively active $[14,26,27]$. Activated oncogenic mutant BRAF has a higher affinity for MEK1 and MEK2 and increases the phosphorylation of MEK. BRAF V600E also potently activates MAPK pathway directly. BRAF can be activated by another genetic rearrangement leading to formation of a fusion protein, AKAP9-BRAF, which can activate MAPK pathways. This rearrangement is present in approximately $11 \%$ of PTC [28]. The basis of these mutations is not known. The BRAF V600E mutant does not seem related to radiation exposure. In contrast, the AKAP9-BRAF is thought to be related to irradiation [28-30].

Some authors suggest that PTCs with BRAF mutations are more aggressive and tend to present at a more advanced clinical stage and with extrathyroidal invasion [24, 31]. BRAF mutations are more frequently present in older patients with otherwise classical PTC, who are at a more advanced stage of the disease at the time of diagnosis [24, 31, 32]. This suggestion is also supported by the observation that the tallcell variant of PTC has a high prevalence of BRAF mutations [33]. Additionally, BRAF mutation is common in aggressive microcarcinomas $[34,35]$. These mutations occur rarely or not at all in follicular or medullary thyroid carcinomas, benign adenomas, or benign hyperplasias [23, 36, 37]. Many undifferentiated and anaplastic carcinomas arising from preexisting PTC have BRAF mutations [32, 38]. Additionally, tumors with BRAF mutations tend to have decreased expression of NIS symporter, and leading the tumor to become refractory to radioiodine treatment [39-41]. Interestingly, BRAF mutation is generally present without other common mutations found in PTC, suggesting that BRAF mutation alone may be sufficient for tumorigenesis [13, 36, 37].

The oncogenic RET/PTC mutation is also commonly found in PTCs, approximately 10-50\% [21]. Familial forms of medullary thyroid carcinoma (MTC) also arise from inheritable activating mutations in RET (the most studied being the C634R change) $[42,43]$. RET/PTC rearrangements are very common in thyroid tissue exposed to radiation, and are also commonly noted in pediatric PTC $[44,45]$. Radiation has been shown to induce this recombination in thyroid cell lines and in normal human thyroid tissue transplanted onto SCID mice [46]. Twelve forms of RET/PTC mutations have been described, with forms 1 and 3 being the most common [16]. RET/PTC1 is typically associated with classical PTC, while RET/PTC3 rearrangement is associated with solid-variant PTCs [17]. These mutations result in the linking of the promoter and N-terminus to unrelated C-terminus fragments of RET, leading to a chimeric receptor that is constitutively active. RET/PTC mutations are uncommon in poorly differentiated cancers, suggesting that this mutation may imply a favorable prognosis [18]. Curiously, RET/PTC expression in thyroid cells has been found to be associated with impaired hormonogenesis and hypothyroidism, particularly Hashimoto's thyroiditis (HT). Whether or not this predisposes an individual with HT to thyroid cancer is unclear [47-49].

2.2. Signaling Kinases. A few of the important signaling cascades being investigated for the possible development of therapeutic kinase inhibitors are the VEGF and PDGF pathways, as well as the PI3K/PTEN pathway. VEGF is a proangiogenic factor that binds to two receptor tyrosine kinases (VEGFR1 and VEGFR-2), of which VEGFR-2 is widely recognized to be the primary mediator of angiogenesis. PDGF-B is required for the maturation of microvasculature, while tumor-derived PDGF-A recruits angiogenic stroma to the tissue. VEGFR and PDGFR mutually support the increased activity of each other [50]. Increased VEGF expression appears to be related to worse prognosis, increased risk of recurrence, and the presence of metastasis $[51,52]$.

The PI3K/PTEN pathway is responsible for regulating glucose metabolism, cell survival, adhesion, and motility [20, $53,54]$. It is found in some thyroid carcinomas (particularly follicular carcinomas) as well as other types of cancers [55$60]$. Epigenetic methylation leads to silencing of the negative 


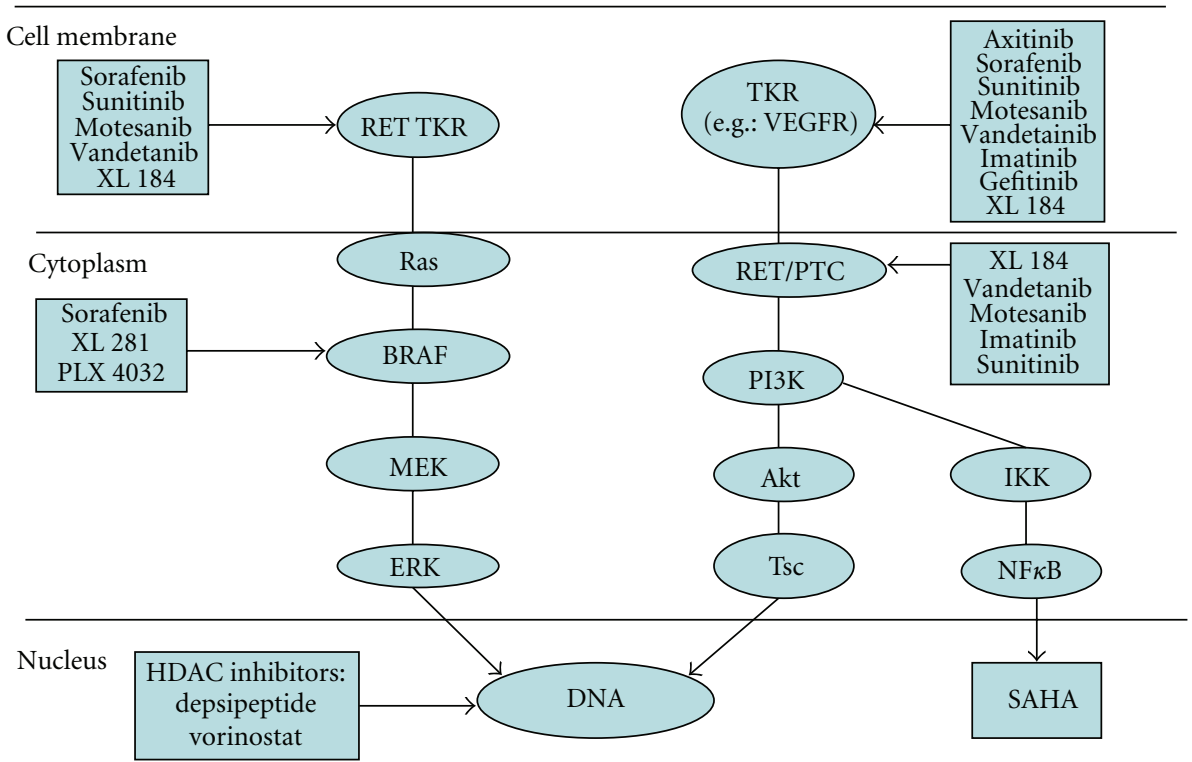

FIGURE 1: Molecular pathways of thyroid cancer and their corresponding therapeutic agents.

regulator PTEN gene, thus facilitating increased activity of the downstream PI3K/Akt pathway [61]. Changes in this pathway occurred in 31\% of benign thyroid adenomas, $24 \%$ of PTCs, $55 \%$ of FTCs, and 58\% of ATCs according to one study. The authors concluded that this pathway may be important in the progression from benign thyroid adenoma to follicular cancer to ATC [62]. BRAF mutations have been found along with mutations in PI3K/PTEN pathway in undifferentiated thyroid carcinoma, perhaps promoting progression from DTC to undifferentiated thyroid cancer [15].

\section{New Agents for the Treatment of Thyroid Cancer}

3.1. Agents Primarily Targeting Oncogenic Kinases. Given the increased frequency of BRAF mutations in PTC, a number of newer therapeutic agents have been developed that inhibit BRAF. The BRAF inhibitor studied most in thyroid cancer is sorafenib. Sorafenib (Nexavar, BAY 439006, Bayer) is an oral tyrosine kinase inhibitor which has been approved by the Food and Drug Administration for the treatment of advanced renal cell carcinoma and unresectable hepatocellular carcinoma. It inhibits VEGFR 2/3, RET including RET/PTC1 mutant, c-kit, PDGFR-beta, and BRAF (including the V600E mutation) [63, 64]. It is a biaryl compound that locks the mutant constitutively active kinase in an inactive state. It competitively inhibits ATP binding in the catalytic domains of both normal and mutant BRAF. This triggers G1 phase arrest.

None of the four phase 1 trials of sorafenib included subjects with thyroid cancer, but there is in vitro data in thyroid cancer cell lines that demonstrated efficacy. The phase 1 trials established the optimum dosing regimen as $400 \mathrm{mg}$ twice a day [65]. A number of phase II trials of sorafenib involved advanced or metastatic DTC. These patients' tumors demonstrated partial responses in 15-27\% of participants, and stable disease in a little over $34-61 \%$ [66-68]. It should be noted that a recent retrospective review of thirteen patients with advanced DTC from MD Anderson demonstrated particular efficacy of this agent in lung metastasis, while it was less efficacious in bone metastasis [69]. Given its ability to interfere with RET and RET/PTC pathways, treatment with sorafenib was attempted in a phase II trial of MTC. Only a very small portion of patients achieved a partial response, although stable disease response rates were comparable to those seen in the DTC phase II trials [70].

While sorafenib is generally well tolerated with side effects including rash, diarrhea, hand-foot syndrome, and fatigue, treatment with sorafenib may be associated with an increased risk of cardiac toxicities, with up to $40 \%$ of patients experiencing EKG changes. Myocardial infarction has also been reported as a side effect of sorafenib in patients being treated for renal cell carcinoma [71, 72]. Increased risk for cutaneous squamous cell carcinomas has been ascribed to the entire class of BRAF inhibitors, and sorafenib is no exception [73].

PLX4032 (RG7204, a Plexxikon drug being codeveloped with Roche) is a 7-azaindole derivative that is currently in clinical trials. PLX4032 specifically inhibits BRAF V600E to a greater extent than wild-type $\operatorname{BRAF}[74,75]$. Unlike sorafenib which only binds to the inactive conformation of BRAF and keeps it inactive, PLX4032 binds to both the active form and inactive forms of BRAF. It has been shown to actively inhibit proliferation of BRAF-mutant-positive cell lines, particularly in melanoma; thus, most of the clinical trials have been focused on melanoma [76].

Notably, not all cell lines with BRAF V600E mutations respond equally to treatment with PLX4032. Although mutant BRAF V600E has been identified in ATC, PLX4032 
did not lead to apoptosis of the anaplastic thyroid carcinoma cell line ARO [77]. Different melanoma cell lines with BRAF V600E demonstrate differential response to PLX4032 as well; some are highly sensitive while some are essentially unresponsive to treatment with this agent. These differences might be explained by whether the cell line is homozygous or heterozygous for the BRAF V600E mutation. Variation in the upregulation of the PI3K/PTEN pathway in response to treatment with this agent potentially mediates the observed resistance in nonresponding cell lines [78].

An early clinical trial of PLX4032 demonstrated that one out of three participants with thyroid cancer achieved a partial response [79]. Rashes are the most common side effect of this agent. Again noted is an increase in risk for development of cutaneous squamous cell carcinomas, likely owing to its anti-BRAF activity [79]. XL281 (Exelixis, BristolMeyers-Squibb BMS-908662) is another oral agent similar to PLX4032 in that it inhibits both wild-type and mutant BRAF kinases. Phase I clinical trials are ongoing and include subjects with thyroid carcinoma though early results are not encouraging [80].

Sunitinib (Sutent, SU11248, Pfizer) is a tyrosine kinase inhibitor affecting VEGFR 1/2/3, RET, RET/PTC1, and RET/PTC3 [81]. Of DTC and MTC patients enrolled in a phase II trial of sunitinib receiving $50 \mathrm{mg} / \mathrm{day}$, partial response was observed in $13 \%$ of patients with DTC, while stable disease was the best response in $68 \%$ of patients with DTC. Eighty-three percent of patients with MTC achieved stable disease [82]. Additionally, there are case reports of patients with advanced MTC having a dramatic response to treatment with sunitinib with respect to both serum calcitonin levels and tumor burden [83]. Patients experience side effects primarily relating to fatigue, and diarrhea when treated with sunitinib. Another unique adverse effect of this agent is palmar-plantar erythrodesia.

Sunitinib can also cause hypothyroidism like many of the tyrosine kinase inhibitors. The mechanism is thought to be related to a destructive thyroiditis when administered for the treatment of renal cell carcinoma $[84,85]$. However, this is unlikely to be the cause of hypothyroidism in thyroid cancer patients, as they have all presumably undergone total thyroidectomy. There is other evidence suggesting that increases in TSH in athyreotic patients are associated with increased type 3 deiodination and augmented peripheral thyroid hormone metabolism [86]. Interestingly, some studies suggest that development of hypothyroidism during treatment for other cancers other than thyroid cancer may actually be an encouraging prognostic factor $[87,88]$.

Heart failure may also be a serious adverse effect sunitinib, occurring in $2.7 \%$ of patients from a retrospective study of 600 patients at MD Anderson [69]. A different retrospective analysis including 75 patients involved in phase I and II trials with sunitinib at several centers around the United States reported an 11\% cardiac event rate, and a decrease in left ventricular ejection fraction of greater than $10 \%$ in $47 \%$ of included subjects. Half of the included patients developed hypertension [89]. While the mechanism of heart failure associated with tyrosine kinase inhibitors may be related to mitochondrial damage, recent studies postulate that myocyte damage occurs secondary to a lack of target selectivity of binding to both tyrosine kinases and serinethreonine kinases [89-91]. Of the clinically available tyrosine kinase inhibitors used in one comparison study, sunitinib, sorafenib, and pazopanib induced the highest degree of myocyte damage as measured by lactate dehydrogenase leakage [90].

Vandetanib (Zactima, ZD6474, iPR Pharmaceuticals, AstraZeneca Pharmaceuticals) is an oral tyrosine kinase inhibitor that targets VEGFR 2/3, RET, and EGFR [92, 93]. It is a heteroaromatic-substituted anilinoquinazoline. It specifically inhibits RET/PTC1 and RET/PTC3 in PTC, and M918R RET mutations in MEN2B [94, 95]. Recent investigations into the mechanism of action of vandetanib in cell culture revealed that the agents ability to block both RET and EGFR simultaneously can prevent escape from RET blockade [96]. A completed phase II trial demonstrated efficacy in metastatic familial MTC [97]; $21 \%$ of patients treated with $300 \mathrm{mg} /$ day showed a partial response, while $53 \%$ patients had stable disease at 24 weeks. There was a decrease in levels of calcitonin in most patients. Adverse effects were significant enough to require dose reductions in several subjects and consisted of diarrhea, severe rash, fatigue, and QTC prolongation [97].

The vandetanib safety database, which accrues data from treatment of multiple cancer types, noted a potential increase in other serious entities such as cerebrovascular accidents and interstitial lung disease [98]. Recent US Food and Drug Administration review cites concern regarding the side effect profile of this agent and propose limiting the indications to progressive symptomatic disease [98]. Another recently published study of subjects with locally advanced or metastatic hereditary MTC administered only $100 \mathrm{mg} /$ day of the drug with nearly similar response rates compared to the above study, and was somewhat better tolerated regarding side effects [99]. Other phase II trials for familial MTC and DTC are underway, as are phase III trials for metastatic MTC. Based on the above mentioned trials as well as other recent data, in April 2011, the US Food and Drug Administration approved vandetanib for use in late-stage MTC. This is the first medication approved by the FDA for the treatment of MTC [100].

Imatinib Mesylate (STI571, Gleevec, Novartis) is an oral tyrosine kinase inhibitor (TKI) that suppresses c-ABL mutation, c-KIT, and inhibits RET autophosphorylation [101]. It was first utilized in the 1990s for treatment of BCR/ABL-positive leukemias. In anaplastic thyroid cancer cell lines (FRO and ARO), it caused growth inhibition, but did not inhibit growth in papillary thyroid cancer cell lines [102, 103]. Two small phase II trials of patients with MTC showed only a small percentage of subjects achieving a stable disease as their best tumor response [104, 105]. These patients were treated with $600 \mathrm{mg}$ daily of imatinib. Over half of the patients were noted to have profound hypothyroidism and required significant increases in their need for thyroid hormone.

New agents are also on the horizon, particularly in RETmutant MTC. Withaferin A (WA) is a novel compound which appears effective against MTC cell proliferation in 
culture. WA inhibits both activation and phosphorylation of RET as well as total RET expression. The investigators recently published evidence of its efficacy in a murine model of MTC. Treatment with WA resulted in $80 \%$ regression of tumor volume in the treated animals with a corresponding significant decrease in calcitonin levels. Additionally, all the treated animals were alive at 6 weeks, while essentially all the control animals died by this point in time [106].

3.2. Agents Primarily Targeting Signaling Kinases. Pazopanib (Votrient, GlaxoSmithKline, GW786034) is a second-generation oral small molecule kinase inhibitor that targets VEGFR-1, 2, and 3, as well as alpha and beta PDGFR [107]. There is new data from studies of breast cancer indicating that it also targets multiple forms of Raf, though it likely does not affect the common BRAF V600E mutant [108]. It is approved for use in renal cell carcinoma and is likely effective in other forms of cancer including ovarian cancer, and nonsmall cell lung carcinoma [109-111].

A phase II study completed in early 2009 of thyroid cancer patients led by the Mayo Clinic demonstrated a confirmed partial response rate by RECIST criteria in $49 \%$ of enrolled subjects (18 patients). There were no complete responses [112]. Starting dose was $800 \mathrm{mg}$ per day. Patients able to tolerate maximum doses of the medication significantly decreased their tumor size as compared to those patients unable to tolerate maximum doses of the agent. Although not statistically significant, the subset of patients with FTC attained a partial response more frequently than subjects with PTC. Forty-three percent (43\%) required dose reductions, owing most frequently to fatigue, skin and hair hypopigmentation, diarrhea, and nausea. Nearly $66 \%$ of patients doubled their TSH concentrations. Also of note, three patients $(8 \%)$ developed grade 3 lower gastrointestinal hemorrhage, which according to the authors is similar to the rate noted in trials with Sorafenib [112].

Motesanib (AMG706, Amgen) is an oral tyrosine-kinase inhibitor that inhibits autophosphorylation of RET and also targets VEGFR 1, 2, and 3, PDGFR, and c-KIT. It demonstrates both direct antitumor and antiangiogenic properties [113]. Phase 1 trials were encouraging with 3 DTC patients registering a partial response [114]. A subsequent phase II trial administering $125 \mathrm{mg} /$ day to patients with DTC demonstrated a partial response in $14 \%$ of patients, while $35 \%$ of patients had stable disease after 48 weeks [115]. A separate arm of this study examined a cohort of patients with advanced, progressive, symptomatic, or metastatic MTC. In this MTC cohort, $2 \%$ of patients showed an objective response, $81 \%$ maintained stable disease, and an overall $76 \%$ of patients showed decrease in the size of their target lesions [116]. Motesanib was generally well tolerated in both cohorts with fatigue, nausea, diarrhea, and hypertension comprising the majority of adverse side effects. As a result of treatment with motesanib, greater than $60 \%$ of patients experienced a TSH elevation out of the desired therapeutic range at some time during the study [116]. A recent study of both DTC and MTC revealed that a decrease in soluble VEGFR-2 and a concurrent increase in placental growth factor (PlGF) during the course of treatment with motesanib predicted which patients would respond to treatment with this agent [117].

Axitinib (AG-013736) inhibits VEGFR more specifically than the agents discussed above. A phase I study included patients with thyroid cancer though none demonstrated partial responses [118]. A phase II study using a dose of $5 \mathrm{mg}$ orally two times per day noted partial responses in $31 \%$ of the patients with DTC and in $18 \%$ of the patients with MTC. Side effects included fatigue, stomatitis, and hypertension [119]. Further trials are ongoing.

XL 184 (BMS-907351) inhibits VEGF 1 and 2, C-MET, RET, c-kit, fms-related tyrosine kinase 3 (FLT3), and TIE-2. A unique aspect of this agent is its activity against hepatocyte growth factor (HGF) and C-MET, both of which are overexpressed in PTC [120]. A phase 1 trial was promising; 55\% of 36 patients MTC demonstrated a partial response, and $84 \%$ overall had stable disease [121]. Interestingly, patients both with and without RET mutations responded. A phase III trial exploring XL 184 in MTC is currently underway.

Other recently evaluated novel agents include pyrazolopyrimidine derivatives like CLM3 and CLM29, which also appear to be widely effective against cytoplasmic and receptor ATP competitive tyrosine kinases including RET, EGFR, VEGFR, and angiogenesis pathways. These agents are unique because they induce apoptosis and decrease tumor volume in murine models of dedifferentiated PTC, irrespective of BRAFV600E mutation [122].

\section{Conclusion}

Recent increased incidence of thyroid cancer is associated with a rise in the number of patients with metastatic disease and tumors that are resistant to the effect of radioiodine. Presently, there are no consensus guidelines about safe and effective methods to treat advanced-stage thyroid cancers. However, the recent elucidation of the pathogenesis of thyroid cancer has facilitated the development of new targeted agents intended to have activity against specific biochemical and oncologic pathways. Many of these newer agents being developed and tested are kinase inhibitors that show a promise for improved treatment of advanced DTC, as well as MTC.

In general, options for the chemotherapeutic treatment of advanced-stage thyroid cancers remain limited. The most promising agents display activity against VEGFR, including pazopanib, motesanib, sorafenib, sunitinib, and vandetanib. There is structural similarity between VEGFR and RET kinases, and cross-activity likely occurs perhaps increasing the efficacy of these agents. Interestingly, axitinib (a tyrosine kinase inhibitor that more specifically targets VEGFR) garnered similar promising tumor responses to the above noted multitargeted kinase inhibitors [119]. In addition, the effective targeted kinase inhibitors not only demonstrate specific activity against VEGFR, but also exhibit activity against a wide array of cellular pathways.

Perhaps owing to their wide ranging cellular targets, there are also numerous concerning side effects of these multitargeted kinase inhibitors. Several trials of the above listed agents reported a significant percentage of patients 
requiring a dose reduction during the study period for general tolerability. The most concerning adverse effects are increases in the incidence of cardiomyopathy and associated hypertension and stroke. Additionally, minor-to-severe bleeding (often in the form of gastrointestinal bleeding) should not be overlooked. Trials of motesanib and sunitinib noted increasing TSH values during the course of treatment, placing patients at risk for being on subtherapeutic doses of suppressive thyroid hormone for a period of time.

Other targeted kinase agents have been shown less effective than previously hoped. Imatinib does not appear to be a candidate for further study in MTC, nor does gefitinib which was not discussed in detail because a phase II trial did not demonstrate any partial responses [123]. Agents specifically targeting the BRAF pathway and BRAF V600E are in earlier stages of clinical trials; however, stable disease appears to be the best response achieved in this class of agents, including PLX4032 as well as XL281. The more specific BRAF inhibitors also have concerning side effects, including an increased incidence of squamous cell neoplasms.

Overall, options for targeted therapy of patients with advanced thyroid cancer remain limited. While these agents may improve radiographic tumor response, change in survival is unclear. Most trials have demonstrated that only small percentages of patients achieved partial responses. There has been a lack of complete responses [124]. Current expert opinion advises that these agents be used only in a specific subset of patients. They should be administered only to patients with rapidly progressive radioiodine refractory metastatic disease. Locally recurrent, unresectable cancer which is unresponsive to radiation may also be considered appropriate for treatment [125].

Other lines of research must be pursued including immunotherapy with vaccines and interferon administration, as well as efforts to induce redifferentiation of tumor cells to take up radioiodine with histone deacetylase inhibitors Romidepsin and Vorinostat, for example [126131]. Another area that warrants further investigation is the exploration of biomarkers that may be able to predict response to a given agent, which may help tailor treatment to an individual. Additionally, both in vivo and in vitro chemosensitivity testing is becoming more common, and is currently available in several clinical trials. These tests appear to be most useful in terms of negative predictability, meaning a treatment is very likely to be unsuccessful in vivo if it is unsuccessful in vitro. Unfortunately the positive predictability of such tests is not as robust. There are many diverse challenges to be addressed before chemosensitivity becomes routine $[122,132]$. Promising new studies are being performed investigating combinations of tyrosine kinase inhibitors with other conventional modalities of treatment, like radiation [133]. Much new data is required before such agents are offered routinely for the treatment of advanced or dedifferentiated thyroid cancer.

\section{Conflict of Interests}

The authors declare that there is no conflict of interests.

\section{References}

[1] "Surveillance, Epidemiology, and End Results (S.E.E.R. Program)," Generate custom reports from the cancer statistics review, Seer 9: 1975-2007, December 2010, http://seer.cancer.gov/.

[2] M. J. Schlumberger, "Papillary and follicular thyroid carcinoma," New England Journal of Medicine, vol. 338, no. 5, pp. 297-306, 1998.

[3] M. R. Castro, E. R. Bergert, J. R. Goellner, I. D. Hay, and J. C. Morris, "Immunohistochemical analysis of sodium iodide symporter expression in metastatic differentiated thyroid cancer: correlation with radioiodine uptake," Journal of Clinical Endocrinology and Metabolism, vol. 86, no. 11, pp. 5627-5632, 2001.

[4] L. S. Ward, P. L. Santarosa, F. Granja, L. V. M. Da Assumpção, M. Savoldi, and G. H. Goldman, "Low expression of sodium iodide symporter identifies aggressive thyroid tumors," Cancer Letters, vol. 200, no. 1, pp. 85-91, 2003.

[5] J. A. Fagin, "How thyroid tumors start and why it matters: kinase mutants as targets for solid cancer pharmacotherapy," Journal of Endocrinology, vol. 183, no. 2, pp. 249-256, 2004.

[6] C. Scollo, E. Baudin, J. P. Travagli et al., "Rationale for central and bilateral lymph node dissection in sporadic and hereditary medullary thyroid cancer," Journal of Clinical Endocrinology and Metabolism, vol. 88, no. 5, pp. 2070-2075, 2003.

[7] S. I. Sherman, "Cytotoxic chemotherapy for differentiated thyroid carcinoma," Clinical Oncology, vol. 22, no. 6, pp. 464468, 2010.

[8] M. Xing, "BRAF mutation in thyroid cancer," EndocrineRelated Cancer, vol. 12, no. 2, pp. 245-262, 2005.

[9] G. Salvatore, V. De Falco, P. Salerno et al., "BRAF is a therapeutic target in aggressive thyroid carcinoma," Clinical Cancer Research, vol. 12, no. 5, pp. 1623-1629, 2006.

[10] B. Ouyang, J. A. Knauf, E. P. Smith et al., "Inhibitors of Raf kinase activity block growth of thyroid cancer cells with RET/PTC or BRAF mutations in vitro and in vivo," Clinical Cancer Research, vol. 12, no. 6, pp. 1785-1793, 2006.

[11] P. Hou, E. Bojdani, and M. Xing, "Induction of thyroid gene expression and radioiodine uptake in thyroid cancer cells by targeting major signaling pathways," Journal of Clinical Endocrinology and Metabolism, vol. 95, no. 2, pp. 820-828, 2010.

[12] D. J. Lim, K. H. Baek, Y. S. Lee et al., "Clinical, histopathological, and molecular characteristics of papillary thyroid microcarcinoma," Thyroid, vol. 17, no. 9, pp. 883-888, 2007.

[13] E. T. Kimura, M. N. Nikiforova, Z. Zhu, J. A. Knauf, Y. E. Nikiforov, and J. A. Fagin, "High prevalence of BRAF mutations in thyroid cancer: genetic evidence for constitutive activation of the RET/PTC-RAS-BRAF signaling pathway in papillary thyroid carcinoma," Cancer Research, vol. 63, no. 7, pp. 1454-1457, 2003.

[14] P. T. C. Wan, M. J. Garnett, S. M. Roe et al., "Mechanism of activation of the RAF-ERK signaling pathway by oncogenic mutations of B-RAF," Cell, vol. 116, no. 6, pp. 855-867, 2004.

[15] P. Hou, D. Liu, Y. Shan et al., "Genetic alterations and their relationship in the phosphatidylinositol 3-kinase/Akt pathway in thyroid cancer," Clinical Cancer Research, vol. 13, no. 4, pp. 1161-1170, 2007.

[16] M. Santoro, N. A. Dathan, M. T. Berlingieri et al., "Molecular characterization of RET/PTC3; a novel rearranged version of the RETproto-oncogene in a human thyroid papillary carcinoma," Oncogene, vol. 9, no. 2, pp. 509-516, 1994. 
[17] Y. E. Nikiforov, J. M. Rowland, K. E. Bove, H. MonforteMunoz, and J. A. Fagin, "Distinct pattern of ret oncogene rearrangements in morphological variants of radiationinduced and sporadic thyroid papillary carcinomas in children," Cancer Research, vol. 57, no. 9, pp. 1690-1694, 1997.

[18] G. Tallini, M. Santoro, M. Helie et al., "RET/PTC oncogene activation defines a subset of papillary thyroid carcinomas lacking evidence of progression to poorly differentiated or undifferentiated tumor phenotypes," Clinical Cancer Research, vol. 4, no. 2, pp. 287-294, 1998.

[19] M. D. Ringel, N. Hayre, J. Saito et al., "Overexpression and overactivation of Akt in thyroid carcinoma," Cancer Research, vol. 61, no. 16, pp. 6105-6111, 2001.

[20] H. Sun, R. Lesche, D. M. Li et al., "PTEN modulates cell cycle progression and cell survival by regulating phosphatidylinositol 3,4,5,-trisphosphate and Akt/protein kinase B signaling pathway," Proceedings of the National Academy of Sciences of the United States of America, vol. 96, no. 11, pp. 6199-6204, 1999.

[21] R. Ciampi and Y. E. Nikiforov, "Minireview: RET/PTC rearrangements and braf mutations in thyroid tumorigenesis," Endocrinology, vol. 148, no. 3, pp. 936-941, 2007.

[22] Y. Cohen, M. Xing, E. Mambo et al., "BRAF mutation in papillary thyroid carcinoma," Journal of the National Cancer Institute, vol. 95, no. 8, pp. 625-627, 2003.

[23] E. Puxeddu, S. Moretti, R. Elisei et al., "BRAFV599E mutation is the leading genetic event in adult sporadic papillary thyroid carcinomas," Journal of Clinical Endocrinology and Metabolism, vol. 89, no. 5, pp. 2414-2420, 2004.

[24] R. Elisei, C. Ugolini, D. Viola et al., "BRAFV600E mutation and outcome of patients with papillary thyroid carcinoma: a 15-year median follow-up study," Journal of Clinical Endocrinology and Metabolism, vol. 93, no. 10, pp. 39433949, 2008.

[25] A. M. Costa, A. Herrero, M. F. Fresno et al., "BRAF mutation associated with other genetic events identifies a subset of aggressive papillary thyroid carcinoma," Clinical Endocrinology, vol. 68, no. 4, pp. 618-634, 2008.

[26] H. Davies, G. R. Bignell, C. Cox et al., "Mutations of the BRAF gene in human cancer," Nature, vol. 417, no. 6892, pp. 949-954, 2002.

[27] T. Brummer, H. Naegele, M. Reth, and Y. Misawa, "Identification of novel ERK-mediated feedback phosphorylation sites at the C-terminus of B-Raf," Oncogene, vol. 22, no. 55, pp. 8823-8834, 2003.

[28] R. Ciampi, J. A. Knauf, R. Kerler et al., "Oncogenic AKAP9BRAF fusion is a novel mechanism of MAPK pathway activation in thyroid cancer," Journal of Clinical Investigation, vol. 115, no. 1, pp. 94-101, 2005.

[29] M. N. Nikiforova, R. Ciampi, G. Salvatore et al., "Low prevalence of BRAF mutations in radiation-induced thyroid tumors in contrast to sporadic papillary carcinomas," Cancer Letters, vol. 209, no. 1, pp. 1-6, 2004.

[30] B. J. Collins, A. B. Schneider, R. A. Prinz, and X. Xu, "Low frequency of BRAF mutations in adult patients with papillary thyroid cancers following childhood radiation exposure," Thyroid, vol. 16, no. 1, pp. 61-66, 2006.

[31] M. Xing, W. H. Westra, R. P. Tufano et al., "BRAF mutation predicts a poorer clinical prognosis for papillary thyroid cancer," Journal of Clinical Endocrinology and Metabolism, vol. 90, no. 12, pp. 6373-6379, 2005.

[32] M. N. Nikiforova, E. T. Kimura, M. Gandhi et al., "BRAF mutations in thyroid tumors are restricted to papillary carcinomas and anaplastic or poorly differentiated carcinomas arising from papillary carcinomas," Journal of Clinical Endocrinology and Metabolism, vol. 88, no. 11, pp. 53995404, 2003.

[33] A. J. Adeniran, Z. Zhu, M. Gandhi et al., "Correlation between genetic alterations and microscopic features, clinical manifestations, and prognostic characteristics of thyroid papillary carcinomas," American Journal of Surgical Pathology, vol. 30, no. 2, pp. 216-222, 2006.

[34] I. Sedliarou, V. Saenko, D. Lantsov et al., "The BRAFT1796A transversion is a prevalent mutational event in human thyroid microcarcinoma," International journal of oncology, vol. 25, no. 6, pp. 1729-1735, 2004.

[35] X. Lee, M. Gao, Y. Ji et al., "Analysis of differential BRAFV600E mutational status in high aggressive papillary thyroid microcarcinoma," Annals of Surgical Oncology, vol. 16, no. 2, pp. 240-245, 2009.

[36] M. Frattini, C. Ferrario, P. Bressan et al., "Alternative mutations of BRAF, RET and NTRK1 are associated with similar but distinct gene expression patterns in papillary thyroid cancer," Oncogene, vol. 23, no. 44, pp. 7436-7440, 2004.

[37] P. Soares, V. Trovisco, A. S. Rocha et al., "BRAF mutations and RET/PTC rearrangements are alternative events in the etiopathogenesis of PTC," Oncogene, vol. 22, no. 29, pp. 4578-4580, 2003.

[38] R. M. Quiros, H. G. Ding, P. Gattuso, R. A. Prinz, and X. Xu, "Evidence that one subset of anaplastic thyroid carcinomas are derived from papillary carcinomas due to BRAF and p53 mutations," Cancer, vol. 103, no. 11, pp. 2261-2268, 2005.

[39] C. Durante, E. Puxeddu, E. Ferretti et al., "Brief report: BRAF mutations in papillary thyroid carcinomas inhibit genes involved in iodine metabolism," Journal of Clinical Endocrinology and Metabolism, vol. 92, no. 7, pp. 2840-2843, 2007.

[40] D. Liu, S. Hu, P. Hou, D. Jiang, S. Condouris, and M. Xing, "Suppression of BRAF/MEK/MAP kinase pathway restores expression of iodide-metabolizing genes in thyroid cells expressing the V600E BRAF mutant," Clinical Cancer Research, vol. 13, no. 4, pp. 1341-1349, 2007.

[41] G. Riesco-Eizaguirre, I. Rodríguez, A. De La Vieja et al., "The BRAFV600E oncogene induces transforming growth factor $\beta$ secretion leading to sodium iodide symporter repression and increased malignancy in thyroid cancer," Cancer Research, vol. 69, no. 21, pp. 8317-8325, 2009.

[42] J. A. Fagin, K. Matsuo, A. Karmakar, Dan Lin Chen, S. H. Tang, and H. P. Koeffler, "High prevalence of mutations of the p53 gene in poorly differentiated human thyroid carcinomas," Journal of Clinical Investigation, vol. 91, no. 1, pp. 179-184, 1993.

[43] L. Ludwig, H. Kessler, M. Wagner et al., "Nuclear factor- $\kappa \mathrm{B}$ is constitutively active in C-cell carcinoma and required for RET-induced transformation," Cancer Research, vol. 61, no. 11, pp. 4526-4535, 2001.

[44] A. Bounacer, R. Wicker, B. Caillou et al., "High prevalence of activating ret proto-oncogene rearrangements, in thyroid tumors from patients who had received external radiation," Oncogene, vol. 15, no. 11, pp. 1263-1273, 1997.

[45] C. L. Fenton, Y. Lukes, D. Nicholson, C. A. Dinauer, G. L. Francis, and R. M. Tuttle, "The ret/PTC mutations are common in sporadic papillary thyroid carcinoma of children and young adults," Journal of Clinical Endocrinology and Metabolism, vol. 85, no. 3, pp. 1170-1175, 2000. 
[46] T. Mizuno, K. S. Iwamoto, S. Kyoizumi et al., "Preferential induction of RET/PTC1 rearrangement by X-ray irradiation," Oncogene, vol. 19, no. 3, pp. 438-443, 2000.

[47] A. Wirtschafter, R. Schmidt, D. Rosen et al., "Expression of the RET/PTC fusion gene as a marker for papillary carcinoma in Hashimoto's thyroiditis," Laryngoscope, vol. 107, no. 1, pp. 95-100, 1997.

[48] O. M. Sheils, J. J. O’Leary, V. Uhlmann, K. Lüttich, and E. C. Sweeney, "ret/PTC-1 activation in Hashimoto thyroiditis," International Journal of Surgical Pathology, vol. 8, no. 3, pp. 185-189, 2000.

[49] M. N. Nikiforova, C. M. Caudill, P. Biddinger, and Y. E. Nikiforov, "Prevalence of RET/PTC rearrangements in Hashimoto's thyroiditis and papillary thyroid carcinomas," International Journal of Surgical Pathology, vol. 10, no. 1, pp. $15-22,2002$.

[50] N. Ferrara and R. S. Kerbel, "Angiogenesis as a therapeutic target," Nature, vol. 438, no. 7070, pp. 967-974, 2005.

[51] M. Klein, J. M. Vignaud, V. Hennequin et al., "Increased expression of the vascular endothelial growth factor is a pejorative prognosis marker in papillary thyroid carcinoma," Journal of Clinical Endocrinology and Metabolism, vol. 86, no. 2, pp. 656-658, 2001.

[52] C. M. Lennard, A. Patel, J. Wilson et al., "Intensity of vascular endothelial growth factor expression is associated with increased risk of recurrence and decreased disease-free survival in papillary thyroid cancer," Surgery, vol. 129, no. 5, pp. 552-558, 2001.

[53] A. K. Ghosh, I. Grigorieva, R. Steele, R. G. Hoover, and R. B. Ray, "PTEN transcriptionally modulates c-myc gene expression in human breast carcinoma cells and is involved in cell growth regulation," Gene, vol. 235, no. 1-2, pp. 85-91, 1999.

[54] M. Tamura, J. Gu, E. H. J. Danen, T. Takino, S. Miyamoto, and K. M. Yamada, "PTEN interactions with focal adhesion kinase and suppression of the extracellular matrix-dependent phosphatidylinositol 3-kinase/Akt cell survival pathway," Journal of Biological Chemistry, vol. 274, no. 29, pp. 2069320703, 1999.

[55] P. A. Steck, M. A. Pershouse, S. A. Jasser et al., "Identification of a candidate tumour suppressor gene, MMAC1, at chromosome 10 q23.3 that is mutated in multiple advanced cancers," Nature Genetics, vol. 15, no. 4, pp. 356-362, 1997.

[56] D. S. Byun, K. Cho, B. K. Ryu et al., "Frequent monoallelic deletion of PTEN and its reciprocal associatioin with PIK3CA amplification in gastric carcinoma," International Journal of Cancer, vol. 104, no. 3, pp. 318-327, 2003.

[57] T. Kimura, A. Suzuki, Y. Fujita et al., "Conditional loss of PTEN leads to testicular teratoma and enhances embryonic germ cell production," Development, vol. 130, no. 8, pp. 1691-1700, 2003.

[58] S. Wang, A. J. Garcia, M. Wu, D. A. Lawson, O. N. Witte, and $\mathrm{H}$. Wu, "Pten deletion leads to the expansion of a prostatic stem/progenitor cell subpopulation and tumor initiation," Proceedings of the National Academy of Sciences of the United States of America, vol. 103, no. 5, pp. 1480-1485, 2006.

[59] A. Yokomizo, D. J. Tindall, L. Hartmann, R. B. Jenkins, D. I. Smith, and W. Liu, "Mutation analysis of the putative tumor suppressor PTEN/MMAC1 in human ovarian cancer," International Journal of Oncology, vol. 13, no. 1, pp. 101-105, 1998.

[60] M. E. McMenamin, P. Soung, S. Perera, I. Kaplan, M. Loda, and W. R. Sellers, "Loss of PTEN expression in paraffinembedded primary prostate cancer correlates with high
Gleason score and advanced stage," Cancer Research, vol. 59, no. 17, pp. 4291-4296, 1999.

[61] P. Hou, M. Ji, and M. Xing, "Association of PTEN gene methylation with genetic alterations in the phosphatidylinositol 3-kinase/AKT signaling pathway in thyroid tumors," Cancer, vol. 113, no. 9, pp. 2440-2447, 2008.

[62] P. Hou, D. Liu, Y. Shan et al., "Genetic alterations and their relationship in the phosphatidylinositol 3-kinase/Akt pathway in thyroid cancer," Clinical Cancer Research, vol. 13, no. 4, pp. 1161-1170, 2007.

[63] S. M. Wilhelm, C. Carter, L. Tang et al., "BAY 43-9006 exhibits broad spectrum oral antitumor activity and targets the RAF/MEK/ERK pathway and receptor tyrosine kinases involved in tumor progression and angiogenesis," Cancer Research, vol. 64, no. 19, pp. 7099-7109, 2004.

[64] Y. C. Henderson, S. H. Ann, Y. Kang, and G. L. Clayman, "Sorafenib potently inhibits papillary thyroid carcinomas harboring RET/PTC1 rearrangement," Clinical Cancer Research, vol. 14, no. 15, pp. 4908-4914, 2008.

[65] D. Strumberg, J. W. Clark, A. Awada et al., "Safety, pharmacokinetics, and preliminary antitumor activity of sorafenib: a review of four phase I trials in patients with advanced refractory solid tumors," Oncologist, vol. 12, no. 4, pp. 426437, 2007.

[66] V. Gupta-Abramson, A. B. Troxel, A. Nellore et al., "Phase II trial of sorafenib in advanced thyroid cancer," Journal of Clinical Oncology, vol. 26, no. 29, pp. 4714-4719, 2008.

[67] R. T. Kloos, M. D. Ringel, M. V. Knopp et al., "Phase II trial of sorafenib in metastatic thyroid cancer," Journal of Clinical Oncology, vol. 27, no. 10, pp. 1675-1684, 2009.

[68] H. Hoftijzer, K. A. Heemstra, H. Morreau et al., "Beneficial effects of sorafenib on tumor progression, but not on radioiodine uptake, in patients with differentiated thyroid carcinoma," European Journal of Endocrinology, vol. 161, no. 6, pp. 923-931, 2009.

[69] M. E. Cabanillas, S. G. Waguespack, Y. Bronstein et al., "Treatment with tyrosine kinase inhibitors for patients with differentiated thyroid cancer: the M. D. Anderson experience," Journal of Clinical Endocrinology and Metabolism, vol. 95, no. 6, pp. 2588-2595, 2010.

[70] E. T. Lam, M. D. Ringel, R. T. Kloos et al., "Phase II clinical trial of sorafenib in metastatic medullary thyroid cancer," Journal of Clinical Oncology, vol. 28, no. 14, pp. 2323-2330, 2010.

[71] M. Schmidinger, C. C. Zielinski, U. M. Vogl et al., "Cardiac toxicity of sunitinib and sorafenib in patients with metastatic renal cell carcinoma," Journal of Clinical Oncology, vol. 26, no. 32, pp. 5204-5212, 2008.

[72] Y. Arima, S. Oshima, K. Noda et al., "Sorafenib-induced acute myocardial infarction due to coronary artery spasm," Journal of Cardiology, vol. 54, no. 3, pp. 512-515, 2009.

[73] J. P. Arnault, J. Wechsler, B. Escudier et al., "Keratoacanthomas and squamous cell carcinomas in patients receiving sorafenib," Journal of Clinical Oncology, vol. 27, no. 23, pp. e59-e61, 2009.

[74] G. Bollag, P. Hirth, J. Tsai et al., "Clinical efficacy of a RAF inhibitor needs broad target blockade in BRAF-mutant melanoma," Nature, vol. 467, no. 7315, pp. 596-599, 2010.

[75] E. W. Joseph, C. A. Pratilas, P. I. Poulikakos et al., "The RAF inhibitor PLX4032 inhibits ERK signaling and tumor cell proliferation in a V600E BRAF-selective manner," Proceedings of the National Academy of Sciences of the United States of America, vol. 107, no. 33, pp. 14903-14908, 2010. 
[76] P. Salerno, V. De Falco, A. Tamburrino et al., "Cytostatic activity of adenosine triphosphate-competitive kinase inhibitors in BRAF mutant thyroid carcinoma cells," Journal of Clinical Endocrinology and Metabolism, vol. 95, no. 1, pp. 450-455, 2010.

[77] E. Sala, L. Mologni, S. Truffa, C. Gaetano, G. E. Bollag, and C. Gambacorti-Passerini, "BRAF silencing by short hairpin RNA or chemical blockade by PLX4032 leads to different responses in melanoma and thyroid carcinoma cells," Molecular Cancer Research, vol. 6, no. 5, pp. 751-759, 2008.

[78] J. N. Søndergaard, R. Nazarian, Q. Wang et al., "Differential sensitivity of melanoma cell lines with BRAFV600Emutation to the specific Raf inhibitor PLX4032," Journal of Translational Medicine, vol. 8, article 39, 2010.

[79] K. T. Flaherty, I. Puzanov, K. B. Kim et al., "Inhibition of mutated, activated BRAF in metastatic melanoma," New England Journal of Medicine, vol. 363, no. 9, pp. 809-819, 2010.

[80] G. K. Schwartz, S. Robertson, A. Shen et al., "A Phase I study of XL281, a selective oral RAF kinase inhibitor, in patients with advanced solid tumors," Journal of Clinical Oncology, vol. 27, no. 15s, abstract 3513, 2009.

[81] D. W. Kim, Y. S. Jo, H. S. Jung et al., "An orally administered multitarget tyrosine kinase inhibitor, SU11248, is a novel potent inhibitor of thyroid oncogenic RET/papillary thyroid cancer kinases," Journal of Clinical Endocrinology and Metabolism, vol. 91, no. 10, pp. 4070-4076, 2006.

[82] E. E. W. Cohen, B. M. Needles, K. J. Cullen et al., "Phase II study of sunitinib in refractory thyroid cancer," Journal of Clinical Oncology, vol. 26, abstract 6025, 2008.

[83] M. J. Bugalho, R. Domingues, and A. Borges, "A case of advanced medullary thyroid carcinoma successfully treated with sunitinib," Oncologist, vol. 14, no. 11, pp. 1083-1087, 2009.

[84] D. Mannavola, P. Coco, G. Vannucchi et al., "A novel tyrosine-kinase selective inhibitor, sunitinib, induces transient hypothyroidism by blocking iodine uptake," Journal of Clinical Endocrinology and Metabolism, vol. 92, no. 9, pp. 3531-3534, 2007.

[85] E. Wong, L. S. Rosen, M. Mulay et al., "Sunitinib induces hypothyroidism in advanced cancer patients and may inhibit thyroid peroxidase activity," Thyroid, vol. 17, no. 4, pp. 351355, 2007.

[86] M. B. Bass, S. I. Sherman, M. J. Schlumberger et al., "Biomarkers as predictors of response to treatment with motesanib in patients with progressive advanced thyroid cancer," Journal of Clinical Endocrinology and Metabolism, vol. 95, no. 11, pp. 5018-5027, 2010.

[87] V. Baldazzi, R. Tassi, A. Lapini, C. Santomaggio, M. Carini, and R. Mazzanti, "The impact of sunitinib-induced hypothyroidism on progression-free survival of metastatic renal cancer patients: a prospective single-center study," Urologic Oncology: Seminars and Original Investigations. In press.

[88] M. Schmidinger, U. M. Vogl, M. Bojic et al., "Hypothyroidism in patients with renal cell carcinoma: blessing or curse?" Cancer, vol. 117, no. 3, pp. 534-544, 2011.

[89] T. F. Chu, M. A. Rupnick, R. Kerkela et al., "Cardiotoxicity associated with tyrosine kinase inhibitor sunitinib," Lancet, vol. 370, no. 9604, pp. 2011-2019, 2007.

[90] B. B. Hasinoff and D. Patel, "The lack of target specificity of small molecule anticancer kinase inhibitors is correlated with their ability to damage myocytes in vitro," Toxicology and Applied Pharmacology, vol. 249, no. 2, pp. 132-139, 2010.
[91] M. H. Chen, R. Kerkelä, and T. Force, "Mechanisms of cardiac dysfunction associated with tyrosine kinase inhibitor cancer therapeutics," Circulation, vol. 118, no. 1, pp. 84-95, 2008.

[92] S. R. Wedge, D. J. Ogilvie, M. Dukes et al., "ZD6474 inhibits vascular endothelial growth factor signaling, angiogenesis, and tumor growth following oral administration," Cancer Research, vol. 62, no. 16, pp. 4645-4655, 2002.

[93] F. Ciardiello, R. Caputo, V. Damiano et al., "Antitumor effects of ZD6474, a small molecule vascular endothelial growth factor receptor tyrosine kinase inhibitor, with additional activity against epidermal growth factor receptor tyrosine kinase," Clinical Cancer Research, vol. 9, no. 4, pp. 1546-1556, 2003.

[94] R. S. Herbst, J. V. Heymach, M. S. O’Reilly, A. Onn, and A. J. Ryan, "Vandetanib (ZD6474): an orally available receptor tyrosine kinase inhibitor that selectively targets pathways critical for tumor growth and angiogenesis," Expert Opinion on Investigational Drugs, vol. 16, no. 2, pp. 239-249, 2007.

[95] F. Carlomagno, D. Vitagliano, T. Guida et al., "ZD6474, an orally available inhibitor of KDR tyrosine kinase activity, efficiently blocks oncogenic RET kinases," Cancer Research, vol. 62, no. 24, pp. 7284-7290, 2002.

[96] D. Vitagliano, V. De Falco, A. Tamburrino et al., "The tyrosine kinase inhibitor ZD6474 blocks proliferation of RET mutant medullary thyroid carcinoma cells," EndocrineRelated Cancer, vol. 18, no. 1, pp. 1-11, 2011.

[97] S. A. Wells Jr., J. E. Gosnell, R. F. Gagel et al., "Vandetanib for the treatment of patients with locally advanced or metastatic hereditary medullary thyroid cancer," Journal of Clinical Oncology, vol. 28, no. 5, pp. 767-772, 2010.

[98] "FDA Briefing Document Oncologic Drugs Advisory Committee Meeting," December 2010, http://www.fda.gov/downloads/AdvisoryCommittees/CommitteesMeetingMaterials/ Drugs/OncologicDrugsAdvisoryCommittee/UCM235086 .pdf.

[99] B. G. Robinson, L. Paz-Ares, A. Krebs, J. Vasselli, and R. Haddad, "Vandetanib $(100 \mathrm{mg})$ in patients with locally advanced or metastatic hereditary medullary thyroid cancer," Journal of Clinical Endocrinology and Metabolism, vol. 95, no. 6, pp. 2664-2671, 2010.

[100] United States Food and Drug Administration Press Release, "FDA approves new treatment for rare form of thyroid cancer," April 2011, http://www.fda.gov/NewsEvents/Newsroom/PressAnnouncements/ucm250168.htm.

[101] M. Carroll, S. Ohno-Jones, S. Tamura et al., "CGP 57148, a tyrosine kinase inhibitor, inhibits the growth of cells expressing BCR-ABL, TEL-ABL, and TEL-PDGFR fusion proteins," Blood, vol. 90, no. 12, pp. 4947-4952, 1997.

[102] A. Podtcheko, A. Ohtsuru, S. Tsuda et al., "The selective tyrosine kinase inhibitor, STI571, inhibits growth of anaplastic thyroid cancer cells," Journal of Clinical Endocrinology and Metabolism, vol. 88, no. 4, pp. 1889-1896, 2003.

[103] J. M. Dziba and K. B. Ain, "Imatinib mesylate (Gleevec; STI571) monotherapy is ineffective in suppressing human anaplastic thyroid carcinoma cell growth in vitro," Journal of Clinical Endocrinology and Metabolism, vol. 89, no. 5, pp. 2127-2135, 2004.

[104] J. W. B. De Groot, B. A. Zonnenberg, P. Q. Van UffordMannesse et al., "A phase II trial of imatinib therapy for metastatic medullary thyroid carcinoma," Journal of Clinical Endocrinology and Metabolism, vol. 92, no. 9, pp. 3466-3469, 2007. 
[105] K. Frank-Raue, M. Fabel, S. Delorme, U. Haberkorn, and F. Raue, "Efficacy of imatinib mesylate in advanced medullary thyroid carcinoma," European Journal of Endocrinology, vol. 157, no. 2, pp. 215-220, 2007.

[106] A. K. Samadi, R. Mukerji, A. Shah, B. N. Timmermann, and M. S. Cohen, "A novel RET inhibitor with potent efficacy against medullary thyroid cancer in vivo," Surgery, vol. 148, no. 6, pp. 1228-1236, 2010.

[107] R. Kumar, V. B. Knick, S. K. Rudolph et al., "Pharmacokinetic-pharmacodynamic correlation from mouse to human with pazopanib, a multikinase angiogenesis inhibitor with potent antitumor and antiangiogenic activity," Molecular Cancer Therapeutics, vol. 6, no. 7, pp. 2012-2021, 2007.

[108] B. Gril, D. Palmieri, Y. Qian et al., "Pazopanib reveals a role for tumor cell B-Raf in the prevention of HER2+ breast cancer brain metastasis," Clinical Cancer Research, vol. 17, no. 1, pp. 142-153, 2011.

[109] M. Friedlander, K. C. Hancock, D. Rischin et al., "A Phase II, open-label study evaluating pazopanib in patients with recurrent ovarian cancer," Gynecologic Oncology, vol. 119, no. 1, pp. 32-37, 2010.

[110] N. Altorki, M. E. Lane, T. Bauer et al., "Phase II proof-ofconcept study of pazopanib monotherapy in treatment-naive patients with stage I/II resectable non-small-cell lung cancer," Journal of Clinical Oncology, vol. 28, no. 19, pp. 3131-3137, 2010.

[111] J. E. Ward and W. M. Stadler, "Pazopanib in renal cell carcinoma," Clinical Cancer Research, vol. 16, no. 24, pp. 5923-5927, 2010.

[112] K. C. Bible, V. J. Suman, J. R. Molina et al., "Efficacy of pazopanib in progressive, radioiodine-refractory, metastatic differentiated thyroid cancers: results of a phase 2 consortium study," The Lancet Oncology, vol. 11, no. 10, pp. 962-972, 2010.

[113] A. Polverino, A. Coxon, C. Starnes et al., "AMG 706, an oral, multikinase inhibitor that selectively targets vascular endothelial growth factor, platelet-derived growth factor, and kit receptors, potently inhibits angiogenesis and induces regression in tumor xenografts," Cancer Research, vol. 66, no. 17, pp. 8715-8721, 2006.

[114] L. S. Rosen, R. Kurzrock, M. Mulay et al., "Safety, pharmacokinetics, and efficacy of AMG 706, an oral multikinase inhibitor, in patients with advanced solid tumors," Journal of Clinical Oncology, vol. 25, no. 17, pp. 2369-2376, 2007.

[115] S. I. Sherman, L. J. Wirth, J. P. Droz et al., "Motesanib diphosphate in progressive differentiated thyroid cancer," New England Journal of Medicine, vol. 359, no. 1, pp. 31-42, 2008.

[116] M. J. Schlumberger, R. Elisei, L. Bastholt et al., "Phase II study of safety and efficacy of motesanib in patients with progressive or symptomatic, advanced or metastatic medullary thyroid cancer," Journal of Clinical Oncology, vol. 27, no. 23, pp. 3794-3801, 2009.

[117] M. B. Bass, S. I. Sherman, M. J. Schlumberger et al., "Biomarkers as predictors of response to treatment with motesanib in patients with progressive advanced thyroid cancer," Journal of Clinical Endocrinology and Metabolism, vol. 95, no. 11, pp. 5018-5027, 2010.

[118] H. S. Rugo, R. S. Herbst, G. Liu et al., "Phase I trial of the oral antiangiogenesis agent AG-013736 in patients with advanced solid tumors: pharmacokinetic and clinical results," Journal of Clinical Oncology, vol. 23, no. 24, pp. 5474-5483, 2005.

[119] E. E. W. Cohen, L. S. Rosen, E. E. Vokes et al., "Axitinib is an active treatment for all histologic subtypes of advanced thyroid cancer: results from a phase II study," Journal of Clinical Oncology, vol. 26, no. 29, pp. 4708-4713, 2008.

[120] R. Mineo, A. Costantino, F. Frasca et al., "Activation of the Hepatocyte Growth Factor (HGF)-Met system in papillary thyroid cancer: biological effects of HGF in thyroid cancer cells depend on Met expression levels," Endocrinology, vol. 145, no. 9, pp. 4355-4365, 2004.

[121] R. Kurzrock, S. Sherman, D. Hong et al., "A Phase I study of XL184, a MET, VEGFR2, and RET kinase inhibitor, administered orally to patients with advanced malignancies, including a subgroup of patients with medullary thyroid carcinoma," in the EORTC-NCI-AACR International Conference on Molecular Targets and Cancer Therapeutics, Geneva, Switzerland, October 2008, poster number 379.

[122] A. Antonelli, G. Bocci, C. La Motta et al., "Novel pyrazolopyrimidine derivatives as tyrosine kinase inhibitors with antitumoral activity in vitro and in vivo in papillary dedifferentiated thyroid cancer," Journal of Clinical Endocrinology and Metabolism, vol. 96, no. 2, pp. E288-E296, 2011.

[123] N. A. Pennell, G. H. Daniels, R. I. Haddad et al., "A phase II study of gefitinib in patients with advanced thyroid cancer," Thyroid, vol. 18, no. 3, pp. 317-323, 2008.

[124] S. I. Sherman, “Targeted therapy of thyroid cancer," Biochemical Pharmacology, vol. 80, no. 5, pp. 592-601, 2010.

[125] J. A. Fagin, R. M. Tuttle, and D. G. Pfister, "Harvesting the low-hanging fruit: kinase inhibitors for therapy of advanced medullary and nonmedullary thyroid cancer," Journal of Clinical Endocrinology and Metabolism, vol. 95, no. 6, pp. 2621-2624, 2010.

[126] F. Furuya, H. Shimura, H. Suzuki et al., "Histone deacetylase inhibitors restore radioiodide uptake and retention in poorly differentiated and anaplastic thyroid cancer cells by expression of the sodium/iodide symporter thyroperoxidase and thyroglobulin," Endocrinology, vol. 145, no. 6, pp. 28652875, 2004.

[127] J. A. Woyach, R. T. Kloos, M. D. Ringel et al., "Lack of therapeutic effect of the histone deacetylase inhibitor vorinostat in patients with metastatic radioiodine-refractory thyroid carcinoma," Journal of Clinical Endocrinology and Metabolism, vol. 94, no. 1, pp. 164-170, 2009.

[128] F. Furuya, H. Shimura, H. Suzuki et al., "Histone deacetylase inhibitors restore radioiodide uptake and retention in poorly differentiated and anaplastic thyroid cancer cells by expression of the sodium/iodide symporter thyroperoxidase and thyroglobulin," Endocrinology, vol. 145, no. 6, pp. 28652875, 2004.

[129] P. Hou, E. Bojdani, and M. Xing, "Induction of thyroid gene expression and radioiodine uptake in thyroid cancer cells by targeting major signaling pathways," Journal of Clinical Endocrinology and Metabolism, vol. 95, no. 2, pp. 820-828, 2010.

[130] G. Vitale, P. Tagliaferri, M. Caraglia et al., "Slow release lanreotide in combination with interferon- $\alpha 2 \mathrm{~b}$ in the treatment of symptomatic advanced medullary thyroid carcinoma," Journal of Clinical Endocrinology and Metabolism, vol. 85, no. 3, pp. 983-988, 2000.

[131] T. Bachleitner-Hofmann, J. Friedl, M. Hassler et al., "Pilot trial of autologous dendritic cells loaded with tumor lysate(s) from allogeneic tumor cell lines in patients with metastatic medullary thyroid carcinoma," Oncology Reports, vol. 21, no. 6, pp. 1585-1592, 2009.

[132] R. D. Blumenthal and D. M. Goldenberg, "Methods and goals for the use of in vitro and in vivo chemosensitivity testing," Molecular Biotechnology, vol. 35, no. 2, pp. 185-197, 2007. 
[133] T. J. Kruser, D. L. Wheeler, E. A. Armstrong et al., "Augmentation of radiation response by motesanib, a multikinase inhibitor that targets vascular endothelial growth factor receptors," Clinical Cancer Research, vol. 16, no. 14, pp. 36393647, 2010. 


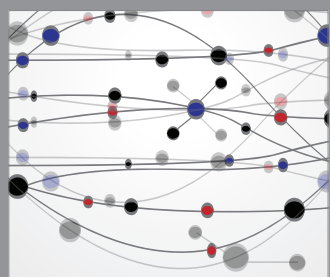

The Scientific World Journal
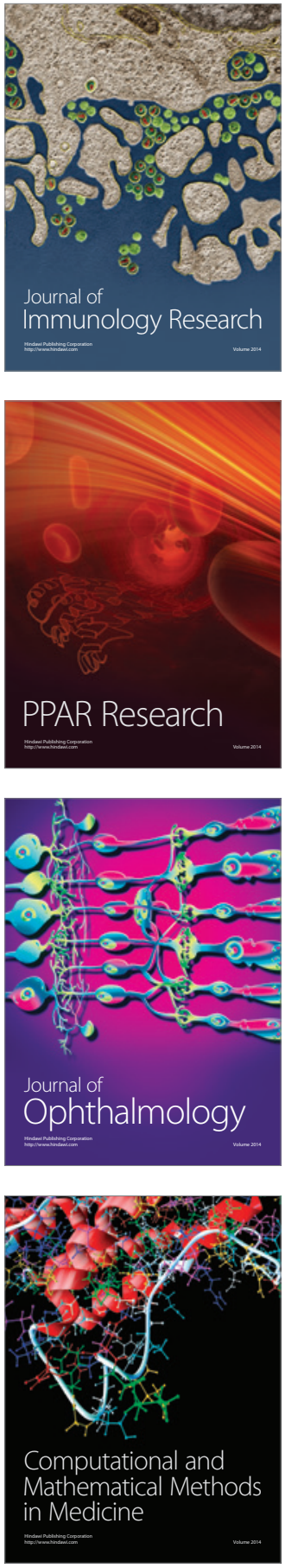

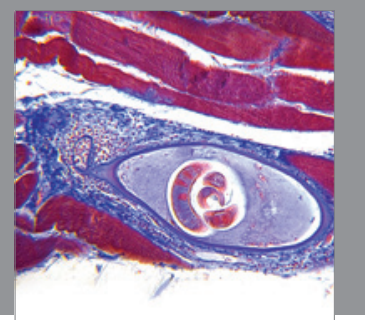

Gastroenterology

Research and Practice
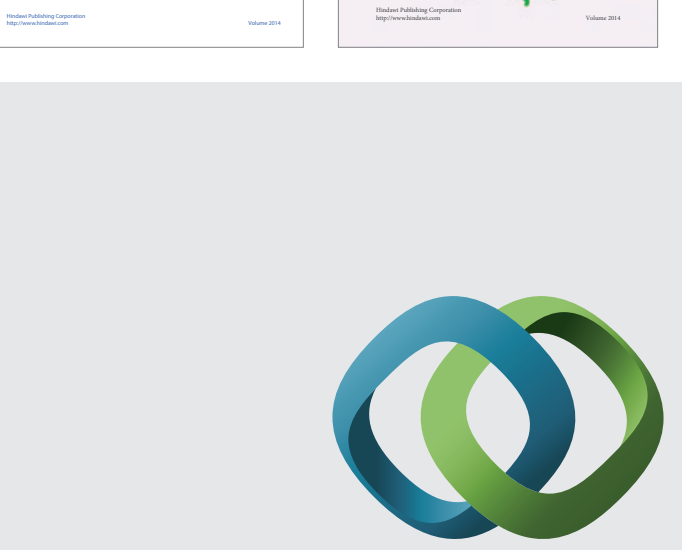

\section{Hindawi}

Submit your manuscripts at

http://www.hindawi.com
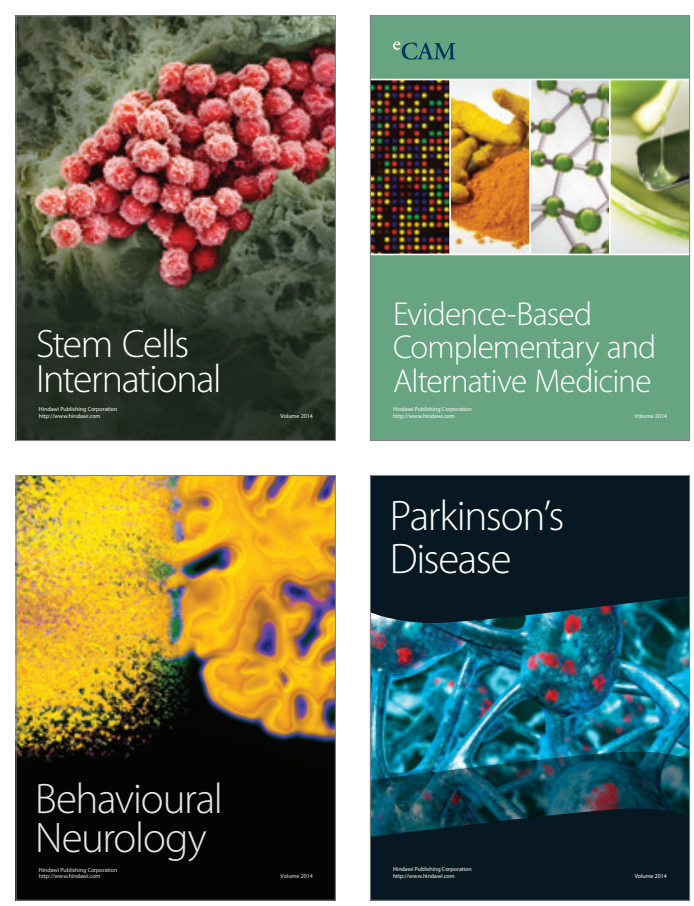

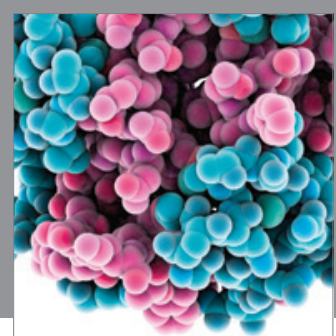

Journal of
Diabetes Research

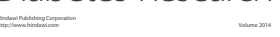

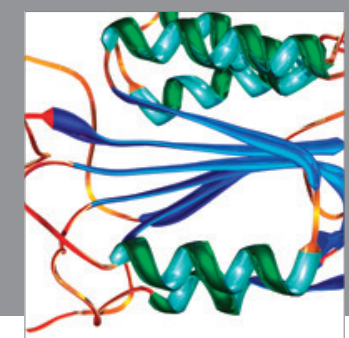

Disease Markers
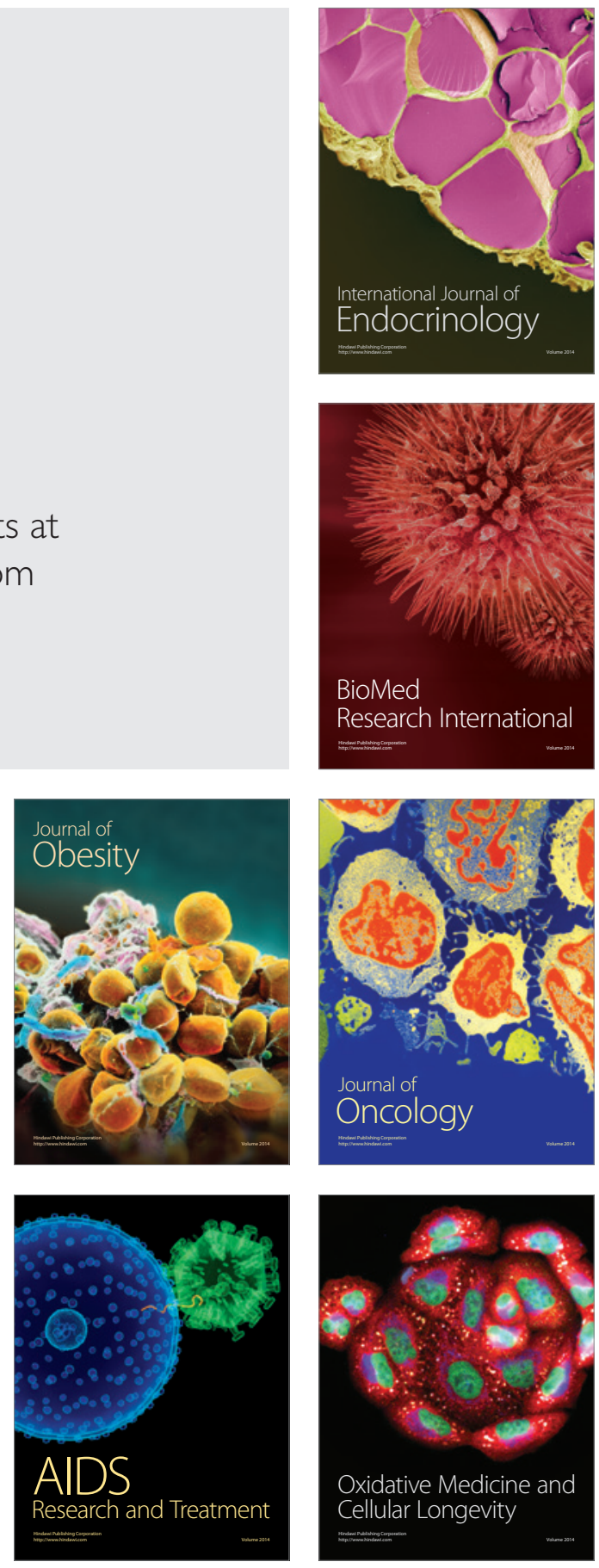